\title{
Relationship between Overweight and Obesity Prevalence and School Proficiency, Performance and Satisfaction Scores among Hawaii Children Entering Public Schools
}

\author{
Ann Pobutsky ${ }^{1}$ and Earl Bradbury ${ }^{2}$ \\ ${ }^{1}$ Hawaii State Department of Health and University of Hawaii at Manoa \\ ${ }^{2}$ Public Health Prevention Service Residency Program, SciMetrika LLC, Durham, NC
}

\begin{abstract}
Background: Previous research suggests that overweight/obese children entering schools in Hawaii are more likely to live in communities with higher proportions of families with low educational attainment, higher poverty, unemployment and government assistance. Purpose: Although studies have highlighted the association between neighborhood structural factors and childhood overweight/obesity, any role between childhood overweight/obesity and educational performance factors remains unclear. Methods: Hawaii public school data were obtained, specifically (1) the proportion of students in 2007-2008 who were overweight/obese (among 12,823 students between ages 4-5 who entered 204 public elementary schools at that time) and (2) average school performance scores on educational performance indicators (math and reading proficiency, school performance, and parent, student and teacher satisfaction (positive responses on school quality indicators). Information for each school was entered into a database and correlational analyses were conducted. Results: Overall school performance scores were moderately correlated with proportion of overweight and obese students (Pearson's $\mathrm{r}=.507, \mathrm{p}<.001$ ). Specifically, schools with lower average performance scores had higher rates of childhood overweight/obesity. Conclusions: Since many children who are entering public schools are already overweight/obese, the findings suggest that educational performance factors measured may be reflective of the community structural factors (social determinants, socio-economic conditions etc.) that are related to overweight/obesity. Addressing community structural factors, including socio-economic conditions, will be important in effectively addressing pediatric obesity.
\end{abstract}

(c) 2015 Californian Journal of Health Promotion. All rights reserved.

Keywords: childhood overweight, childhood obesity, Hawaii, educational performance, school performance, math proficiency, reading proficiency

\section{Introduction}

Obesity in childhood is associated with numerous health problems. Obese or overweight children are at increased risk for numerous health conditions, including type- 2 diabetes, hypertension, cardiovascular disease, dyslipidemia (high triglyceride levels), some cancers, gallstones, osteoarthritis, rheumatoid arthritis, premature death, sleep apnea, and respiratory problems, as well as poorer physical functioning status and lower life expectancy (Centers for Disease Control and Prevention, 2014).
In July 2013 the rates of obesity and overweight among children aged 4 to 5 years entering public schools during 2007-2008 in Hawaii were reported (Pobutsky, Bradbury, Reyes-Salvail, \& Kishaba, 2013). The results showed that over one in four (28.6\%) children were either overweight or obese. These findings were similar to those found 2002-2003 (Pobutsky, Hitokawa, Zou, Huang, Rosen, \& Wood, 2006). School complexes in Hawaii, which are similar to school districts, are geographically grouped and comprise those elementary and middle schools that feed into a particular high school. Total proportions overweight and obese were higher in specific school complexes on Oahu, as 
well as in specific rural and Neighbor Island school complexes. The 2013 findings also showed that the school complex communities with the highest proportions of overweight and obese children also had higher proportions of families with lower educational levels and per capita income, as well as higher poverty, unemployment and persons needing government assistance (State of Hawaii, 2009).

Although studies have highlighted the association between neighborhood structural factors (e.g., high poverty, lower education) and childhood obesity (Graves Grow, Cook, Arterburn, Saelens, Drewenowski, \& Lozano, 2010; Bathell, Simpson, Stumbo, Carle, \& Gombojav, 2010; Tolbert, Kimbro, \& Denney, 2013), the magnitude of the association between educational performance factors (e.g., parent, student and teacher satisfaction and school performance) and childhood obesity remains unclear. The present brief report investigates this issue by plotting the 2007-2008 Hawaii public school level data on the total proportion of entering students who were overweight and obese, and adding in the 2008 school composite (average) scores or educational performance. Specifically, we assessed whether children with higher BMI, an indicator of overweight and obesity were more likely to be attending schools with lower performance indicators in the same vulnerable low SES communities.

\section{Methods}

\section{Participants}

Student Health Records are required for students entering public schools in Hawaii and the Student Health Record document contains the student's required immunization history and must be stamped or signed by a medical practitioner, medical personnel or a clinic. It also contains information on the age and sex of the child along with information regarding existing chronic conditions, such as asthma. Height and weight were measured and recorded by the medical personnel completing the form and it is not known how many different medical personnel completed these forms, and this could have introduced errors. Measurements were recorded in both metric and non-metric measurements, and all records and forms were verified for accuracy and all converted into nonmetric measurements for analysis in CDC EpiInfo 2000 NutStat program (Centers for Disease Control and Prevention, 2014).

All public schools in the entire state (including charter schools), were invited by the Department of Education (DOE) to participate, but schools were not required to participate. There were 14,070 students who entered kindergarten in Hawaii public schools in 2007-2008 (Pobutsky, Bradbury, \& Kishaba, 2013). This study population was limited to those students aged 4 to 5 years (48 to 71 months), resulting in a total of 12,823 usable health records among those who were the correct age for entering kindergarten in 2007-2008 (or 91\% of the total census of entering students). Students' ethnicity, household income or other household characteristics were not included on the Student Health Record. Therefore, these variables were not available to be included in this study. Although information on individual schools was available for the study, and was provided to the $\mathrm{DOE}$, to ensure privacy, results of individual schools were suppressed under an agreement between the $\mathrm{DOH}$ and the DOE, and only reported out by school complex.

\section{Analyses}

The CDC's EpiInfo 2000 NutStat program was used to calculate percentiles for BMI, height for age and weight for height based on the 2000 CDC reference population. The CDC reference population is based on national health surveys from 1963 to 1994 along with supplemental sources, including NHES II \&II, NHANES I, II \& III and others (Centers for Disease Control and Prevention, EpiInfo, 2015). In the CDC reference population, $10 \%$ of children are overweight and 5\% are obese, with a total of $15 \%$ combined as overweight and obese. This study follows the CDC protocol and obesity is defined as BMI > 95th percentile and overweight was defined as being between $>$ 85th and $<$ 95th percentiles

Educational performance factors were operationalized by school "scores" obtained from the Hawaii Department of Education 
(DOE), which is a composite measure of math and reading proficiency, student, parent and teacher satisfaction, and Adequate Yearly Progress (AYP) on No Child Left Behind performance measures for 2008. The school score is (1) an average of five measures of satisfaction and student performance, based on the percentage of parents, teachers and students who gave positive responses on the satisfaction section of the 2007 School Quality Survey, the percentage of students whose proficiency meets or exceeds the Hawaii Content and Performance Standards (HCPSIII) in reading and in math, along with (2) whether or not the school is in good standing under the federal No Child Left Behind Act of 2001 (NCLB) and (3) has met the performance benchmarks that measure

Adequate Yearly Progress (AYP) in in math and reading, participation and proficiency, graduation/retention rates, and other educational indicators, such as teacher qualification. Higher scores reflect higher student proficiency, and school satisfaction and performance measures (Honolulu Magazine, 2008). The proportion of entering students in schools and school complexes who were overweight and obese was calculated based on data obtained from student health records (Form 14), and reported in Pobutsky et al. (2013).

Linear regression was conducted using these data to find the line of best fit, along with a Pearson's regression coefficient of correlation between school scores and proportions overweight and obese.

\section{Results}

School composite scores (average school scores on educational performance of math and reading proficiency, school performance, and parent, student and teacher satisfaction (positive responses on school quality indicators) and the proportion overweight and obese were moderately correlated (Pearson's r=.507, $\mathrm{p}<.001$ ). In Figure 1, higher average school scores on student, parent, and teacher satisfaction and school performance and proficiency were associated with lower proportions of entering students who were overweight and obese. The best fitting regression line for the scatter plot indicated that the proportion of overweight and obese accounted for $25 \%\left(\mathrm{R}^{2}=.257\right)$ of the variance in school scores.

Table 1 shows the proportion and ranking of overweight and obese 4 to 5 year old students for each public school complex, along with its average school composite score on school satisfaction and performance and ranking. The overall general pattern shows lower scores and higher BMI associated with the same school complexes. It is important to point out that there were schools which were exceptions to the general trend in the correlation; the pattern itself is apparent in the rankings even though it is not a one to one ranking match. These communities with the highest proportions of children overweight and obese include those communities with higher proportions of families with lower educational levels, lower per capita income, higher poverty, higher proportions needing government assistance, higher unemployment and include higher proportions of ethnic groups at risk for overweight and obesity, namely Native Hawaiians and other Pacific Islanders and Filipinos. The evidence here shows these are also the communities with overall lower school performance and low satisfaction. 


\section{Table 1.}

Percentage and Ranking of Public School Complexes for Entering Students’ Overweight/Obesity and Average School Score Ranking

\begin{tabular}{|c|c|c|c|c|c|}
\hline County & School Complex & $\begin{array}{c}\% \\
\text { Overweight/Ob } \\
\text { ese in 2007- } \\
2008 \\
\end{array}$ & $\begin{array}{c}\% \\
\text { Overweight/Obese } \\
\text { Ranking in } \\
2007-2008 \\
\end{array}$ & $\begin{array}{c}\text { Average Low } \\
2008 \text { School } \\
\text { Performance Score }\end{array}$ & $\begin{array}{c}\text { Low School } \\
\text { Performance Score } \\
\text { Ranking } 2008\end{array}$ \\
\hline Honolulu/Oahu & Mililani $\quad(\mathrm{N}=616)$ & 39.2 & 1 & 72.5 & 37 \\
\hline Maui & Molokai (N=115) & 39.1 & 2 & 62.8 & 22 \\
\hline Maui & Lanai $(\mathrm{N}=41)$ & 39.0 & 3 & 40.7 & 1 \\
\hline Honolulu/Oahu & Nanakuli (N=263) & 38.4 & 4 & 42.4 & 2 \\
\hline Hawaii & Pahoa $(\mathrm{N}=125)$ & 36.8 & 5 & 43.4 & 3 \\
\hline Hawaii & Keeau $(\mathrm{N}=178)$ & 36.5 & 6 & 53.0 & 10 (tie) \\
\hline Kauai & West Kauai (N=195) & 35.4 & 7 & 69.4 & 34 \\
\hline Honolulu/Oahu & Waialua $(\mathrm{N}=96)$ & 34.4 & 8 & 58.4 & 16 \\
\hline Honolulu/Oahu & Waipahu $\quad(\mathrm{N}=589)$ & 33.9 & 9 & 54.6 & 12 \\
\hline Honolulu/Oahu & Farrington $(\mathrm{N}=547)$ & 33.8 & 10 & 49.6 & 7 \\
\hline Honolulu/Oahu & Kahuku (N=258) & 32.7 & 11 & 66.1 & 28 \\
\hline Honolulu/Oahu & Waianae $(\mathrm{N}=466)$ & 31.7 & 12 & 48.2 & 6 \\
\hline Honolulu/Oahu & Kailua $\quad(\mathrm{N}=380)$ & 31.3 & 13 & 53.0 & 10 (tie) \\
\hline Honolulu/Oahu & Moanalua $(\mathrm{N}=278)$ & 31.0 & 14 & 60.4 & 20 \\
\hline Honolulu/Oahu & Kapolei (N=323) & 30.7 & 15 & 60.0 & 19 \\
\hline Honolulu/Oahu & Leilehua $(\mathrm{N}=652)$ & 30.3 & 16 & 54.9 & 13 \\
\hline Honolulu/Oahu & Kalaheo $(\mathrm{N}=309)$ & 30.1 & 17 & 58.0 & 15 \\
\hline Honolulu/Oahu & Campbell (N=602) & 27.1 & 18 & 63.4 & 25 \\
\hline Honolulu/Oahu & Radford (N=502) & 26.7 & 19 & 61.3 & 21 \\
\hline Honolulu/Oahu & Pearl City (N=508) & 26.6 & 20 & 68.2 & 32 \\
\hline Honolulu/Oahu & Kaimuki $\quad(\mathrm{N}=379)$ & 25.6 & 21 & 63.8 & 26 \\
\hline Honolulu/Oahu & McKinley $(\mathrm{N}=333)$ & 25.5 & 22 & 59.3 & 18 (tie) \\
\hline Honolulu/Oahu & Aiea $(\mathrm{N}=289)$ & 25.2 & 23 & 64.7 & 28 \\
\hline Honolulu/Oahu & Castle $(\mathrm{N}=487)$ & 24.8 & 24 & 59.3 & 18 (tie) \\
\hline Hawaii & North Kona $(\mathrm{N}=219)$ & 24.2 & 25 & 47.2 & 5 \\
\hline Honolulu/Oahu & Roosevelt $(\mathrm{N}=439)$ & 24.2 & 26 & 68.6 & 33 \\
\hline Maui & Lahainaluna (N=224) & 33.5 & 27 & 52.0 & 8 \\
\hline Maui & Hana $(\mathrm{N}=23)$ & 31.8 & 28 & 45.3 & 4 \\
\hline Hawaii & Hilo (N=327) & 31.5 & 29 & 59.2 & 17 \\
\hline Kauai & East Kauai $\quad(\mathrm{N}=185)$ & 31.3 & 30 & 66.4 & 30 \\
\hline Hawaii & Kohala $(\mathrm{N}=64)$ & 31.2 & 31 & 52.5 & 9 \\
\hline Maui & Baldwin $(\mathrm{N}=274)$ & 29.5 & 32 & 68.1 & 31 \\
\hline Maui & Maui $\quad(\mathrm{N}=579)$ & 29.0 & 33 & 64.1 & 27 \\
\hline Hawaii & Kau $\quad(N=78)$ & 28.2 & 34 & 56.4 & 14 \\
\hline Hawaii & Honokaa $(\mathrm{N}=238)$ & 27.3 & 35 & 53.4 & 11 \\
\hline Hawaii & Central Hilo (N=287) & 26.8 & 36 & 66.3 & 29 \\
\hline
\end{tabular}




\section{Table 1 cont'd.}

Percentage and Ranking of Public School Complexes for Entering Students' Overweight/Obesity and Average School Score Ranking

\begin{tabular}{|c|c|c|c|c|c|}
\hline County & School Complex & $\begin{array}{c}\% \\
\text { Overweight/Ob } \\
\text { ese in 2007- } \\
2008\end{array}$ & $\begin{array}{c}\% \\
\text { Overweight/Obese } \\
\text { Ranking in } \\
2007-2008\end{array}$ & $\begin{array}{c}\text { Average Low } \\
2008 \text { School } \\
\text { Performance Score }\end{array}$ & $\begin{array}{c}\text { Low School } \\
\text { Performance Score } \\
\text { Ranking } 2008\end{array}$ \\
\hline Hawaii & South Kona $(\mathrm{N}=167)$ & 25. & 37 & 63.3 & 24 \\
\hline Kauai & Central Kauai $(\mathrm{N}=255)$ & 24.0 & 38 & 63.1 & 23 \\
\hline Maui & Kekaulike $(\mathrm{N}=321)$ & 22.4 & 39 & 70.7 & 35 \\
\hline Honolulu/Oahu & Kalani $(\mathrm{N}=451)$ & 17.3 & 40 & 79.1 & 38 \\
\hline Honolulu/Oahu & Kaiser $(\mathrm{N}=151)$ & 15.3 & 41 & 72.1 & 36 \\
\hline
\end{tabular}

\section{Discussion}

Results of this brief report show that total proportions of entering students who were overweight and obese at both the school and complex was a strong correlate of average overall school performance, proficiency and satisfaction, along with the previously mentioned socio-economic indicators for these specific communities (based on school complex). The same school complex communities with the highest proportions of overweight and obese children also had higher proportions of families with lower educational levels and lower per capita income, as well as higher poverty, unemployment and persons needing government assistance. The exact underlying factors involved in the association between childhood obesity prevalence and poorer educational outcomes found here are not clear but are likely related to the complex interplay of the social determinants of health including household income, housing, neighborhoods and community environments.

\section{Limitations}

Because of the cross-sectional design of the present report, a causal relationship between BMI and educational environment cannot be inferred, nor can a causal link be made directly from the low socio-economic indicators of specific communities and BMI and/or educational environments. However, it is important to point out that having an almost complete census of entering students (91\%) results in having less error than obtaining just a sampling of students.

\section{Conclusion}

The previous analysis in 2013 suggested individual-level behavioral interventions alone are not enough to contain the obesity epidemic, and therefore, increased attention should be paid to the social determinants of health, including the role of neighborhood and community environments and overall health (Pobutsky, Bradbury and Wong Tomiyasu, 2011) . Our results provide additional support for evidence that there are common underlying social and economic processes or determinants responsible for lower school performance and satisfaction scores which in turn, are also correlated with childhood obesity. Indeed, integrated public health interventions that target both community and school level disparities may be effective at reducing overweight and obesity among young children. The Hawaii State Department of Health has developed a framework to begin to address coordinated chronic disease prevention in communities, schools and worksites through such integrated interventions. This framework is available online from: http://health.hawaii.gov/chronic-

disease/files/2014/09/CDFrameworkLR.pdf. The Department of Health has collaborated with the Department of Education's School Food Services Branch (SFSB) to develop (1) healthy standardized recipes and provide opportunities for cafeteria staff training to make the SFSB meal programs more nutritious, and (2) school gardens to increase opportunities for nutrition and cooking education, provide access to fresh fruits and vegetables, and develop positive social 
norms around healthy food consumption. For more information, see http://health.hawaii.gov/school-health/. For other Hawaii integrated initiatives on physical activity and

nutrition, see http://health.hawaii.gov/physical-activitynutrition/

\section{References}

Bathell, L., Simpson, S., Stumbo, Carle, A.C., \& Gombojav, N. (2010). National, state, and local disparities in childhood obesity. Health Affairs, Vol. 29:3: 347-356, March.Centers for Disease Control and Prevention. Childhood obesity facts. Retrieved October 10, 2014 from: http://www.cdc.gov/obesity/data/childhood.html

Centers for Disease Control and Prevention. Childhood obesity facts. Retrieved October 10, 2014 from: http://www.cdc.gov/obesity/data/childhood.html

Centers for Disease Control and Prevention. EpiInfo. Retrieved January 2, 2015 from: http://wwwn.cdc.gov/epiinfo/

Graves Grow H.M., Cook, A.J., Arterburn, D.E., Saelens, B.E., A Drewenowski, A., \& Lozano, P. (2010). Child obesity associated with social disadvantage of children's neighborhoods. Social Science \& Medicine, Vol 71: 584-591.

Hawaii State Department of Health, Chronic Disease Framework. 2014-2020. Retrieved January 2, 2015 from: http://health.hawaii.gov/chronic-disease/files/2014/09/CDFrameworkLR.pdf

Honolulu Magazine's Grading the Public Schools (2008). Retrieved October 7, 2014 from: http://www.honolulumagazine.com/Honolulu-Magazine/May-2008/Grading-the-PublicSchools508/2008-Public-Schools-Database/

Pobutsky, A., Hirokawa, R., Zou, L., Huang, T., Rosen, L., and Wood, B. (2006). Overweight and at-risk for overweight among Hawaii public school students entering kindergarten, 2002-2005. Hawaii Medical Journal, October. Retrieved October 10, 2014 from: www.hjmph.org/HMJ_Oct06.pdf

Pobutsky, A., Bradbury, E., \& Wong Tomiyasu, D. (2011). Chronic disease disparities report 2011: Social Determinants. Hawaii State Department of Health, Chronic Disease Management and Control Branch. Retrieved October 7, 2014 from: http://health.hawaii.gov/chronicdisease/files/2013/12/CD_BurdenReport_FINAL.pdf

Pobutsky, A., Bradbury, E., \& Kishaba, G. (2013). Overweight and obesity among Hawaii public school students entering kindergarten in 2008-2009 and comparison with a similar 2002-2003 Cohort. Hawaii Journal of Medicine and Public Health, July. Retrieved October 7, 2014 from: http://www.hjmph.org/HJMPH_Jul13.pdf and http://www.ncbi.nlm.nih.gov/pmc/articles/PMC3727572/.

State of Hawaii Primary Care Needs Assessment Data Book (2009). Family Health Services Division, Hawaii Department of Health. Retrieved October 7, 2014 from: http://health.hawaii.gov/about/files/2013/06/pcna2012databook.pdf

Tolbert Kimbro, R., \& Denney, J.T.(2013). Neighborhood context and racial/ethnic differences in young children's obesity: Structural barriers to interventions. Social Science \& Medicine, Oct., Vol. 95:97-105.

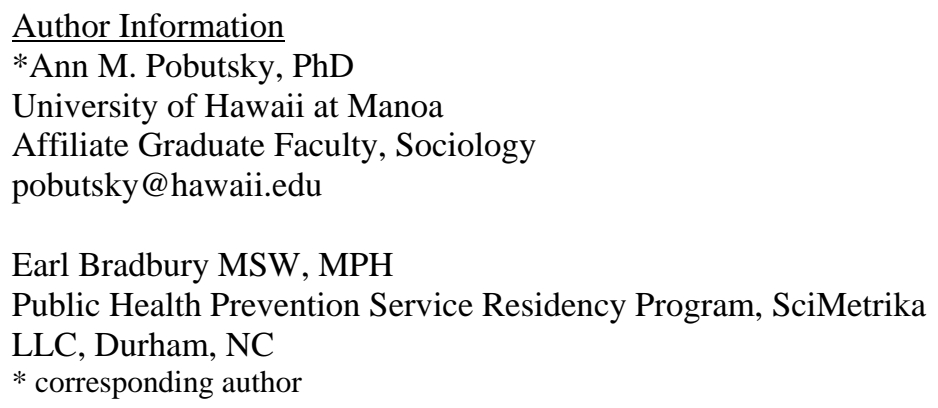

